Int. J. Odontostomat.,

6(3):385-390, 2012.

\title{
Cleidocranial Dysostosis, a Case Report
}

\author{
Disostosis Cleidocraneal, Reporte de Caso
}

Chbicheb, Saliha*; Halimi, Abdelali*; Taleb, B. ${ }^{* * *}$; Zaoui, F. ${ }^{* * *}$ \& El Wady, W. ${ }^{* *}$

CHBICHEB, S.; HALIMI, A.; TALEB, B.; ZAOUI, F. \& EL WADY, W. Cleidocranial dysostosis, a case report. Int. J. Odontostomat., 6(3):385-390, 2012.

ABSTRACT: Cleidocranial dysostosis is a congenital condition that results from faulty development of membranous bones, mainly the clavicles and skull. The clavicular abnormality may range from a small defect in one clavicle to complete absence of both, but most frequently an absence of the central clavicular segment, as was seen in our patient. A review of the literature has revealed only one previous report a cleidocranial dysostosis syndrome.

KEY WORDS: syndrome, cleidocranial dysostosis, unerupted teeth.

\section{INTRODUCTION}

Cleidocranial dysostosis is an autosomal dominant inherited condition transmitted by either sex and affecting men or women with equal frequency. The classic feature is at least one clavicle partly or completely absent. The skull has a brachycephalic appearance, and the closure of the sutures and fontanelles is delayed compared with normal. The fontanelles exhibit secondary ossification centers forming wormian bones. The skull can have parietal and frontal bossing. The patient tends to be short in stature with a narrow chest and sloping shoulders.

Unerupted permanent teeth, supernumerary teeth, and overretained deciduous teeth as well as delayed eruption of teeth, malocclusion, and impacted teeth arc the causes of aberrations in the development of the dentition. Many of the permanent teeth fail to erupt, although permanent teeth that have no deciduous predecessors, such as the molars, usually erupt normally. There is almost total absence of cellular or secondary cementum in all examined teeth. This may be related to the failure of eruption so frequently seen. Some of the impacted teeth may be associated with follicular cysts. There is apparently no predilection for race. Solitary cases with no apparent hereditary influence are occasionally reported as mutations (Lubowitz, 1968; Kelly \& Nakamoto, 1974; Harris et al., 1977).

\section{CASE REPORT}

The patient, a 24 year old white female of Moroccan parents. She was of small stature. She was mentally alert, appeared to be of normal intelligence, and physical defects had been noted at birth, and the patient had spent 7 months at birth.

The family history was traced through the patient's parents on back to the maternal grand parents, and cleidocranial dysostosis was not suspected in any of them. There was a complete aplasia of the clavicles and associated funnelling of the rib cage towards the thoracic inlet (Fig. 1). Abnormalities of the bones of the hands and feet, especially pointing of the terminal phalangeal tufts (Figs. 2 and 3 ).

Clinical examination demonstrating mild frontal hossing, retrusion of the middle face disharmony

\footnotetext{
Professor Aggregate in Surgical Odontology Faculty of the Faculty of Dental Medicine of Rabat, Rabat, Morocco.

- Specialist in Dento-Facial Orthopedics of the Faculty of Dental Medicine of Rabat, Rabat, Morocco.

$* *$ Professor of the Higher Education in Surgical Odontology Faculty of the Faculty of Dental Medicine of Rabat, Rabat, Morocco.

${ }^{* * *+*}$ Professor of the Higher Education in Dento-Facial Orthopedics of the Faculty of Dental Medicine of Rabat, Rabat, Morocco.
} 
between the jaws due to and mandibular prognathism, with long face (Figs. 4 and 5).
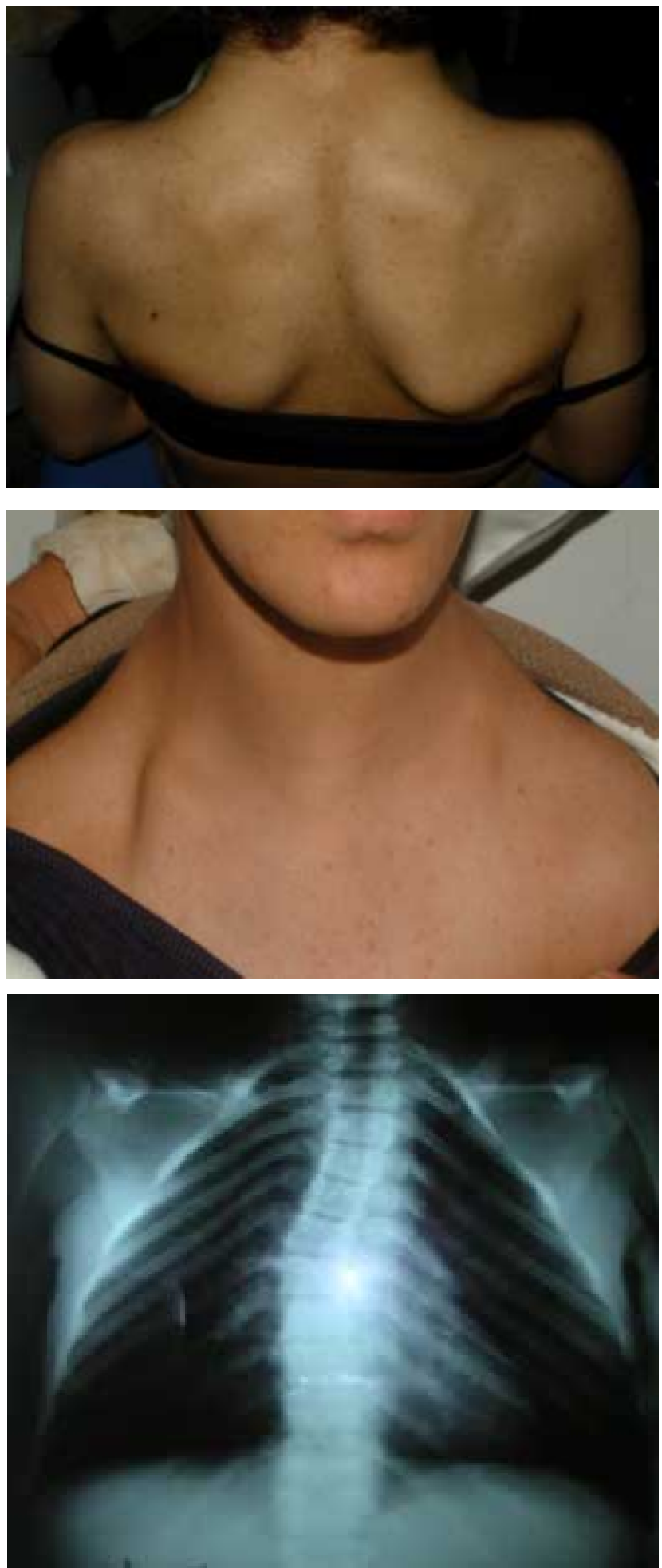

Fig. 1. Complete aplasia of the clavicles and associated funnelling of the rib cage towards the thoracic inlet. And a scoliosis associated.
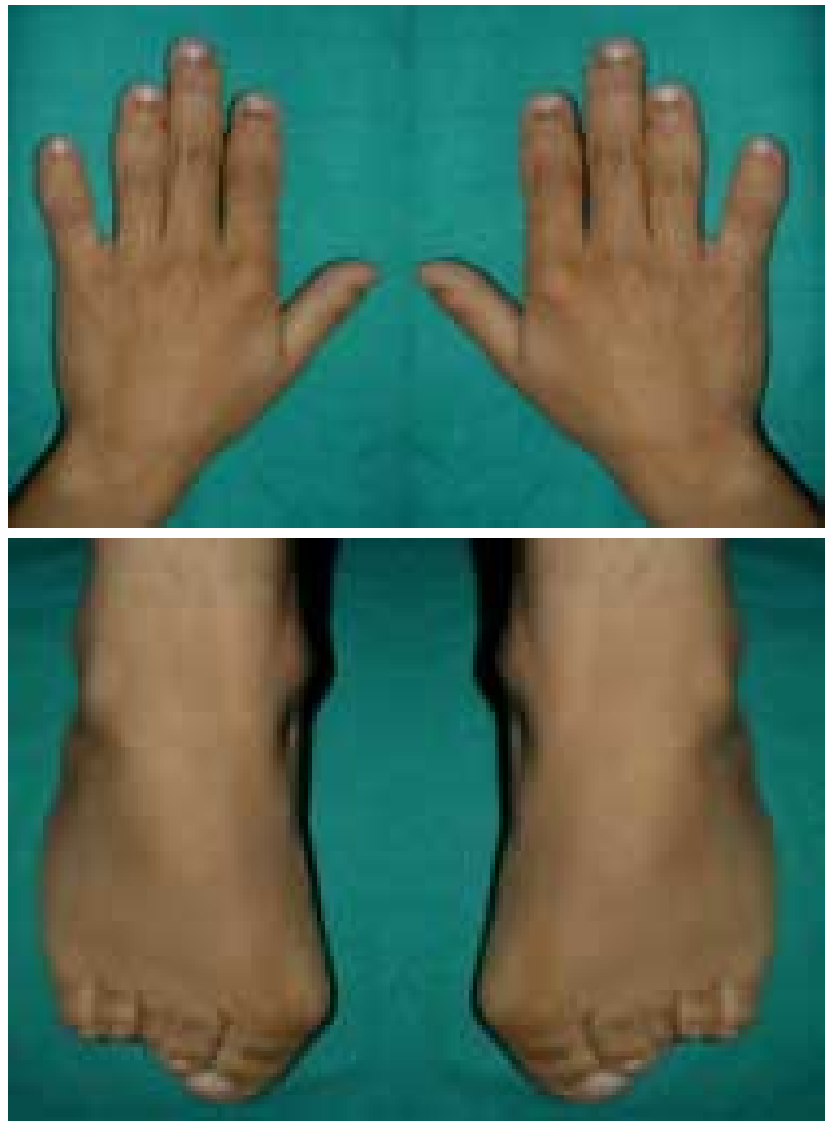

Figs. 2 and 3. Abnormalities of the bones of the hands and feet, especially pointing of the terminal phalangeal tufts.
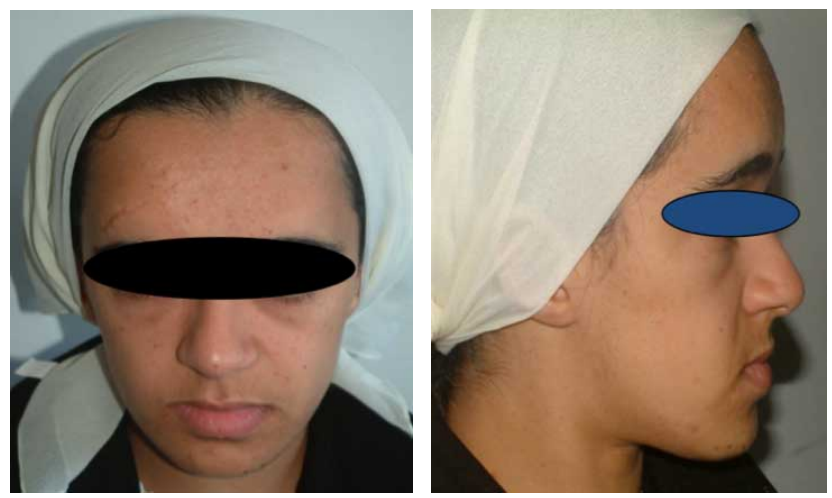

Figs. 4 and 5. Mild frontal hossing, retrusion of the middle face disharmony between the jaws due to and mandibular prognathism, with long face.

The oral soft tissues appeared normal; the uvula was complete, and there was no macroglossia. The palate was highly with maxillary perimeters narrow large mandibulary perimeters (Figs. $6 a$ and b).

The dental examination relieved a maxillary and mandibular discrepancy, absence of $13,23,33,32$, 

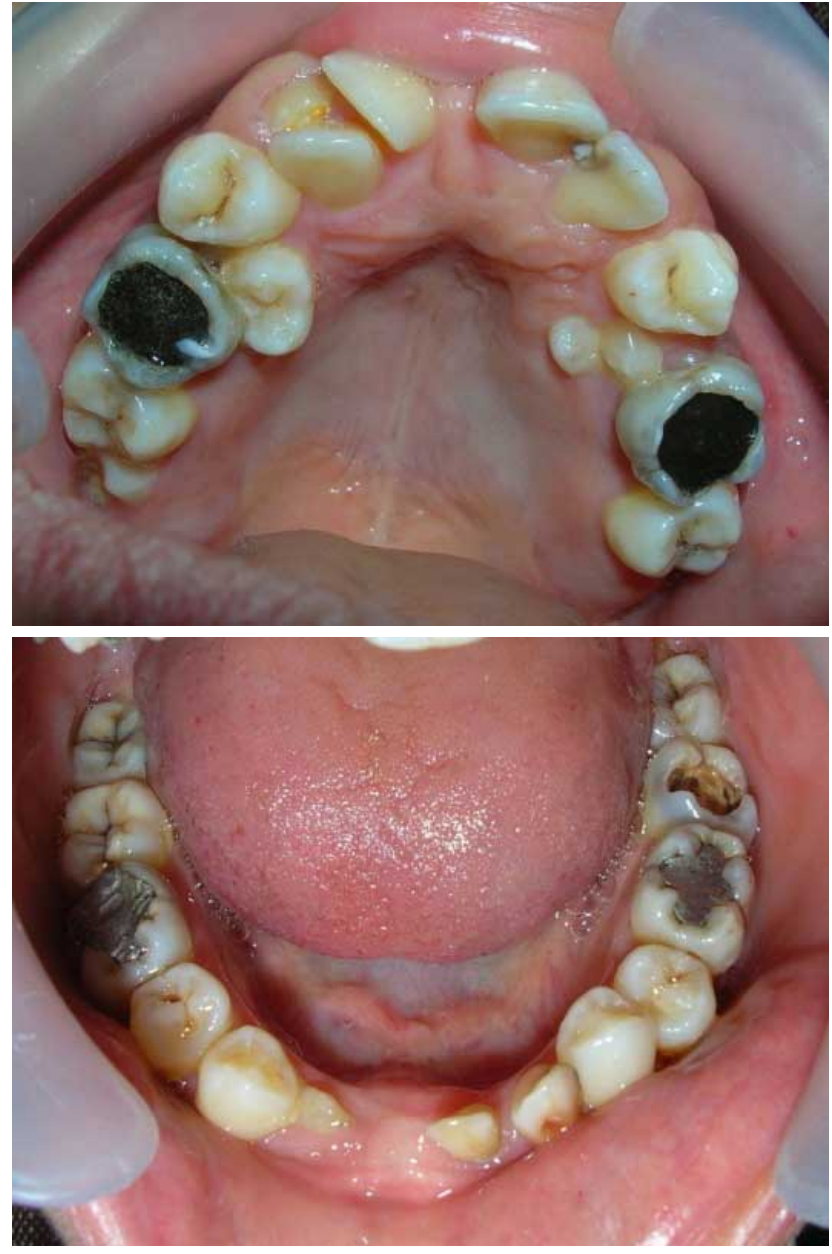

Figs. 6a, b. Intra oral view: The palate was highly with maxillary and mandibular arch perimeter deficiencies. Absence of $13,23,33,32,42$, and 43. Persistence of $73,72$.

42, and 43. Persistence of 73,72 . Bilateral squeletal Cross-bite the first malar to the first malar (Figs. 7a, b and c). An orthopantomograph study showed inclusion 13, 23, 33 32, 42, 43, agenesie of 31, 41 of teeth (Fig. 8).

Lateral cephalometric radiograph revealed mild frontal hossing, retrusion of the middle face disharmony between the jaws due to and mandibular prognathism, and posterieor rotation of the mandibule and maxillary and mandibular arch perimeter deficiencies (Fig. 9).

\section{DISCUSSION}

This disorder was first reported in medical literature in 1765. Marie and Sainton described the condition in 1898 and gave it the name cleidocranial dysostosis (Magnus \& Sands, 1974).
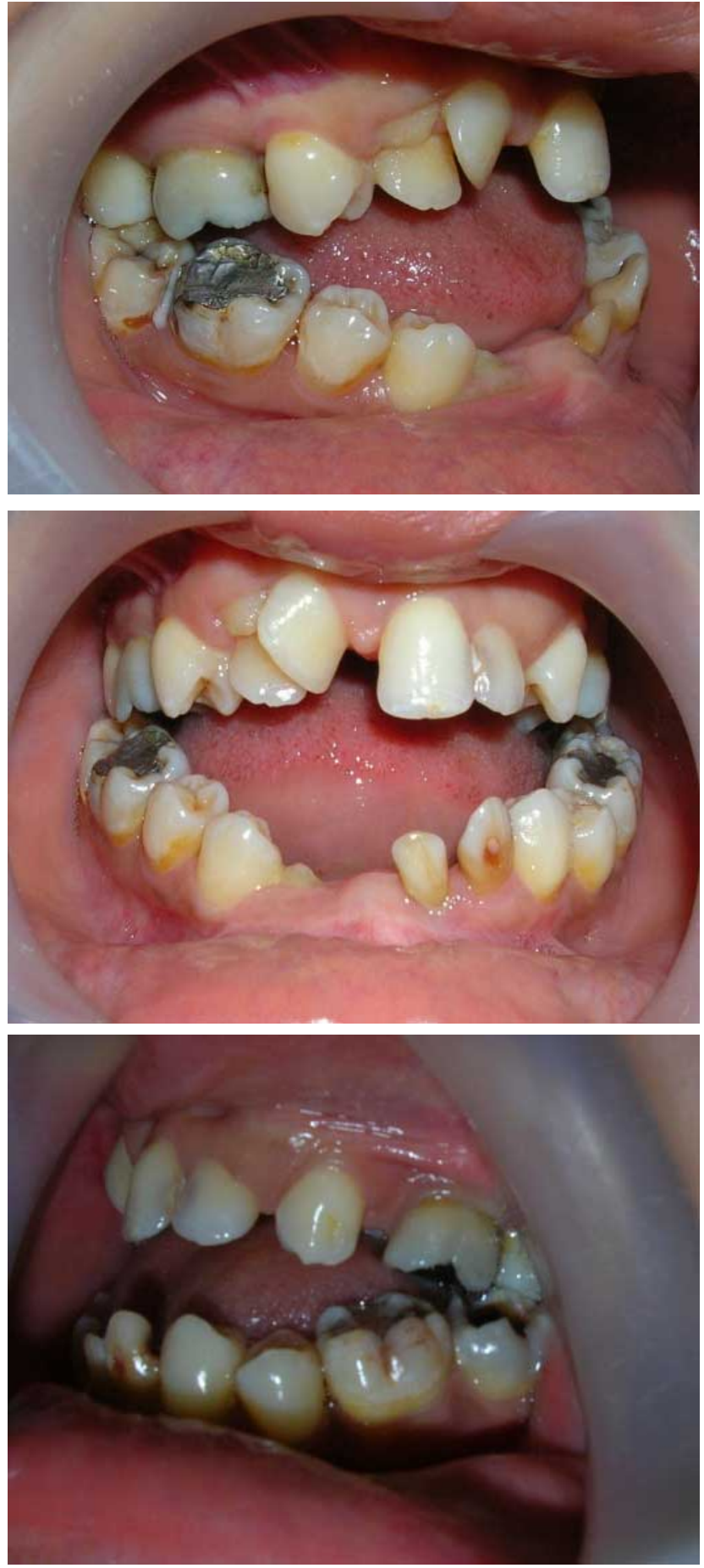

Figs. $7 a, b, c$. Intra oral view : maxillary and mandibular discrepancy. Bilateral squeletal Cross-bite the first molar to the first molar.

The aetiology of the failure of eruption of the dentition in cleidocranial dysostosis is of immense interest as are all disease processes, the abnormal may illuminate the normal. In the developing child this 


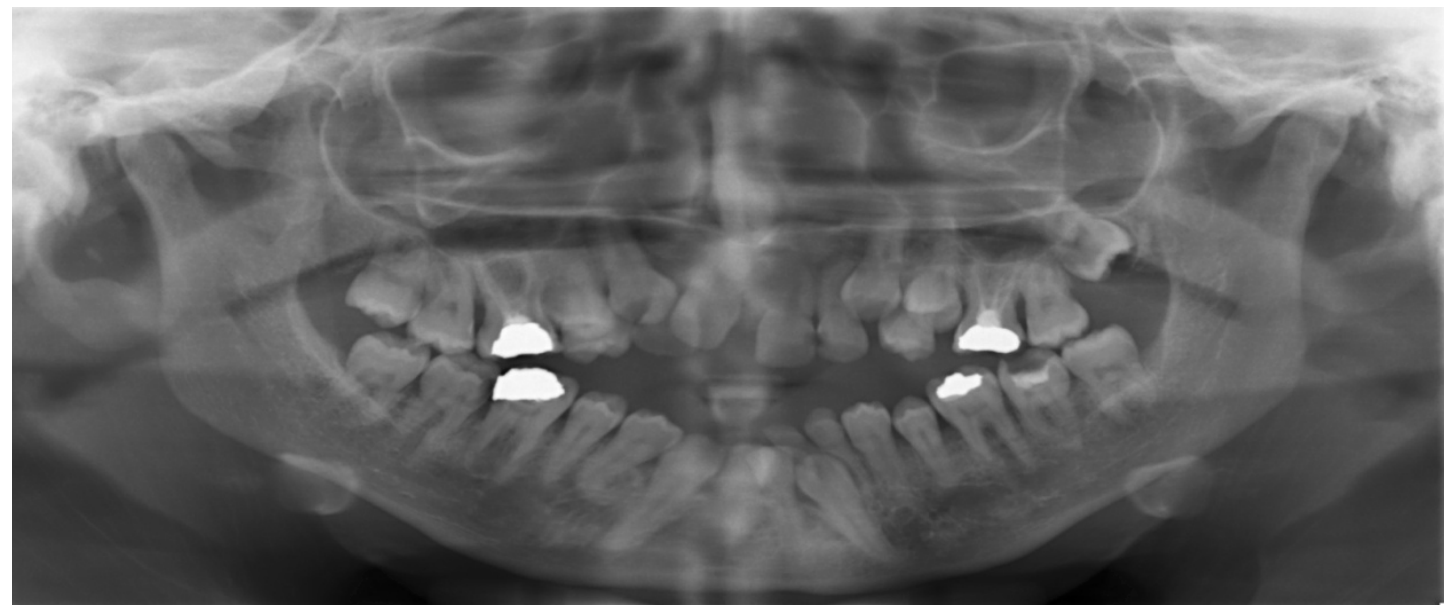

Fig. 8. An orthopantomograph study showed inclusion 13, 23, 33 32, 42, 43, agenesie of 31 , 41 of teeth.

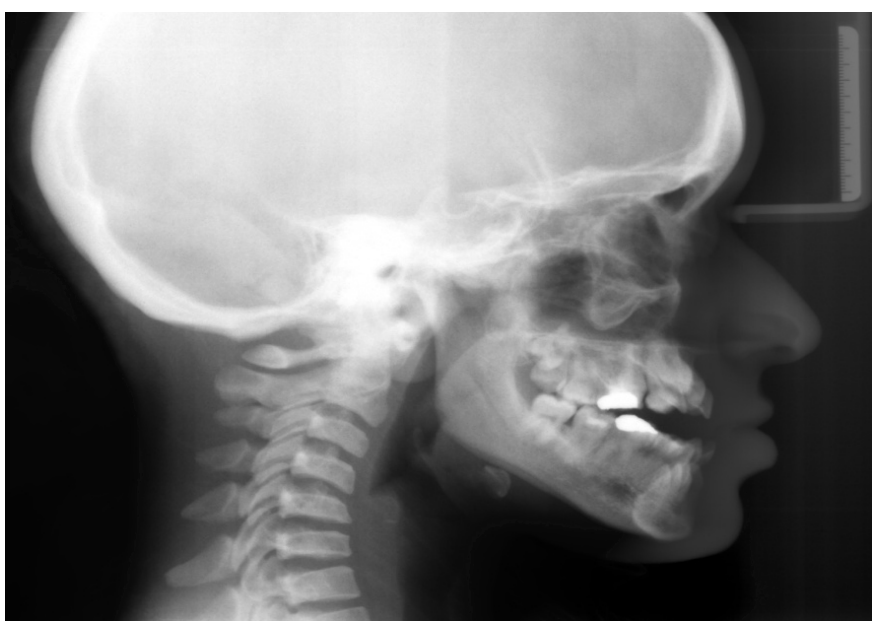

Fig. 9. Lateral cephalometric radiograph demonstrating, transitional Class III malocclusion with mild frontal hossing, and mandibular prognathism.

will include a failure of resorption of the roots of the deciduous dentition, as this note also calcification of a new supernumerary adjacent as also brought about by large multinucleated giant cells lying in Howships lacunae on the roots of the deciduous dentition.

This concept is supported firstly by the normal appearance of the deciduous dentition, the crowns of which have no bony obstacle in their paths of eruption, and the usually slightly delayed but full eruption of the first permanent molars which only have a thin covering of bone. Secondly by the non eruption of the permanent incisors, canines, and premolars which, at the chronological times for their eruption, have considerable distance to travel through the investing bone. In addition they normally rely on the shedding of the deciduous teeth for their appearance in the mouth (Migliorisi \& Blenkinsopp, 1980).
The frequently reported abnormality of inadequate deformed spike-shaped roots, crown distortion and hypoplasia in areas of compression from adjacent teeth, strongly suggests a disturbance in bony remodelling, to accommodate the developing dentition and later eruption

Moreover Hitchin noted histological findings in extracted teeth from patients with cleidocranial dysostosis suggestive of flattening of the epithelial sheath of Hertwig, and that the spiked apices arose from growth of this same sheath into the only space available, namely the bony neuro-vascular canals. In addition those teeth which have been surgically exposed, or by this hypothesis, decompressed, and the case described in this paper, later show normal straight tapering root formation without distortion (Migliorisi \& Blenkinsopp).

The absence of cellular cementum as originally reported by Rushton is difficult to elucidate. He observed histologically an almost total absence of this cementum on the roots of the unerupted incisors that were extracted from a patient with cleidocranial dysostosis, and this was true for one erupted lower incisor that was also removed. The deciduous dentition, however, had a normal complement of cementum. He also demonstrated cellular cementum in the sectioned roots of unerupted teeth of people not affected by the disease. Normally cellular cementum is a prominent feature of the premolar and molar dentition and tends to be confined to the apical portion of the root, with its thickness increasing apically (Migliorisi \& Blenkinsopp). 
The fact that in the normal person cellular cementum may be sparse or absent from incisor teeth, that it is predominantly a feature of the apical third, that is, that part of the root which is formed once the tooth has erupted, and that it may be deposited in large amounts with age at the apices to compensate for attrition, suggests a more important role in the process of passive eruption rather than active eruption. Histological examination of four exposed and subsequently functional permanent incisor teeth in a patient with the disease, demonstrated the presence of normal acellular cementum and definite evidence of formation of some cellular cementum (Migliorisi \& Blenkinsopp; Angle \& Rebellato, 2005).

General physical findings: the closure of the fontanels and sutures in the cranium is delayed, sometimes throughout life. Frontal, parietal, and occipital bossing is present, and the skull is wide and short (brachycephalic) with slight depressions along the suture lines. The clavicles may be hypoplastic or totally absent. Deficiency or absence of the clavicles usually results in a long neck and narrow, sloping shoulders which permit the individual to bring the shoulders together in front of the chest. There are variations in the size, origin, and insertion of muscles related to the clavicles, but these patients seem to have remarkably little loss of function and may be muscular and active. Deviations from normal in other bones may or may not be present and may range from an underdeveloped pelvis to changes in the metacarpals and middle and terminal phalanges of the hands. Individuals may be of short stature. Mentality in these patients is generally normal (Järvinen, 1981; Lubowitz; Harris et al.; Magnus \& Sands).

Dental findings: the oral cavity usually exhibits a high arched palate, and a submucous or complete cleft is not uncommon. The deciduous dentition is retained, and the permanent teeth remain unerupted along with multiple supernumerary teeth; cyst formation being a possible sequel.

The maxillae are underdeveloped, while growth of the mandible is normal. The underdeveloped maxillae together with the resulting overclosure give the patient a prognathic appearance, although the mandible is of normal size (Järvinen).

The dental defects are curious and bizarre. The deciduous teeth erupt normally. All of the permanent teeth generally lose their eruption stimulus and stay embedded, while the deciduous teeth are retained. In some instances, the molar teeth that are not succedaneous to deciduous teeth erupt in their proper places posterior to the deciduous dentition. However, extraction of the deciduous teeth does not stimulate the eruption of the permanent teeth.

In addition to the retention of deciduous teeth and noneruption of permanent teeth. There is a high incidence of supernumerary teeth. These teeth, like the permanent teeth, generally remain embedded in the bone. The supernumerary teeth arc so numerous in some patients as to constitute a third dentition. The radiographs present a strange conglomeration of retained deciduous teeth, perhaps a few erupted permanent teeth, and most of the permanent teeth together with supernumerary teeth deeply embedded in the bone. Unerupted teeth are so numerous that they often fill the entire body of the mandible.

The radiographs are so typical of the disorder that they point to a diagnosis of cleidocranial dysostosis (Migliorisi \& Blenkinsopp).

Treating patients with cleidocranial dysostosis requires a dedicated and knowledgeable team of dental specialists illustrates well the good results with may be obtained from consultation management of patients with complex problems (Angle \& Rebellato).

CONCLUSION. Cleidocranial dysostosis is an autosomal dominant. The diagnostic was based upon a clinical and radiographic examination. The coordination of treatment planned in stages by several disciplines within dentistry.

CHBICHEB, S.; HALIMI, A.; TALEB, B.; ZAOUI, F. \& EL WADY, W. Disostosis cleidocraneal, reporte de caso. Int. J. Odontostomat., 6(3):385-390, 2012.

RESUMEN: La disostosis cleidocraneal es una condición congénita que resulta de un desarrollo defectuoso de los huesos con osificación membranosa, principalmente las clavículas y el cráneo. La anormalidad clavicular puede ir desde un pequeño defecto en una clavícula hasta la total ausencia de ambas, pero con mayor frecuencia se observa la ausencia del segmento clavicular central, como se observó en nuestro paciente. Una revisión de la literatura reveló sólo un caso previo con un síndrome de disostosis cleidocraneal de características similares.

PALABRAS CLAVE: síndrome, disostosis cleidocraneal, dientes no erupcionados. 


\section{REFERENCES}

Angle, A. D. \& Rebellato, J. Dental team management for a patient with cleidocranial dysostosis. Am. J. Orthod. Dentofacial Orthop., 128(1):110-7, 2005.

Harris, R. J.; Gaston, G. W.; Avery, J. E. \& McCuen, J. M. Mandibular prognathism and apertognathia associated with cleidocranial dysostosis in a father and son. Oral Surg. Oral Med. Oral Pathol., 44(6):830-6, 1977.

Järvinen, S. Cephalometric findings in three cases of cleidocranial dysostosis. Am. J. Orthod., 79(2):184-91, 1981.

Kelly, E. \& Nakamoto, R. Y. Cleidocranial dysostosis--a prosthodontic problem. J. Prosthet. Dent., 31(5):518-26, 1974.

Lubowitz, A. H. Cleidocranial dysostosis: a case report. Angle Orthod., 38(2):150-4, 1968.

Magnus, W. W. \& Sands, N. R. Cleidocranial dysostosis. Report of a case. Am. J. Orthod., 65(6):638-43, 1974.

Migliorisi, J. A. \& Blenkinsopp, P. T. Oral surgical management of cleidocranial dysostosis. Br. J. Oral Surg., 18(3):21220, 1980.
Correspondence to:

Chbicheb Saliha

Professor Aggregate in Surgical Odontology Faculty

Faculty of Dental Medicine of Rabat

Rabat

MOROCCO

Tel: 0021266285639

Email: Halimiali111@yahoo.fr

Received: 08-10-2012

Accepted: 12-11-2012 